\title{
Fungal diversity and Aspergillus in hospital environments
}

\author{
Erick Obed Martínez-Herrera', María Guadalupe Frías-De-León², Esperanza Duarte-Escalante³, \\ María del Carmen Calderón-Ezquerro ${ }^{4}$, María del Carmen Jiménez-Martínez ${ }^{5,6}$, \\ Gustavo Acosta-Altamirano ${ }^{7}$, Facundo Rivera-Becerril ${ }^{8}$, Conchita Toriello ${ }^{3}$, \\ María del Rocío Reyes-Montes ${ }^{3}$ \\ ${ }^{1}$ Doctorado en Ciencias Biológicas y de la Salud, Universidad Autónoma Metropolitana-Xochimilco, México \\ ${ }^{2}$ División de Investigación, Hospital Juárez de México. Av. Instituto Politécnico Nacional, México \\ ${ }^{3}$ Departamento de Microbiología y Parasitología, Facultad de Medicina, Universidad Nacional Autónoma de México \\ (UNAM), Mexico \\ ${ }^{4}$ Centro de Ciencias de la Atmósfera, Universidad Nacional Autónoma de México (UNAM), Mexico \\ ${ }^{5}$ Unidad de Investigación, Instituto de Oftalmología "Fundación de Asistencia Privada Conde de Valenciana, IAP", México \\ ${ }^{6}$ Departamento de Bioquímica, Facultad de Medicina, Universidad Nacional Autónoma de México (UNAM), Mexico \\ ${ }^{7}$ Instituto de Seguridad y Servicios Sociales de los Trabajadores del Estado, Mexico \\ ${ }^{8}$ Departamento el Hombre y su Ambiente, Universidad Autónoma Metropolitana-Xochimilco, México
}

Martínez-Herrera EO, Frías-De-León MG, Duarte-Escalante E, Calderón-Ezquerro MC, Jiménez-Martínez MC, Acosta-Altamirano G, RiveraBecerril F, Toriello C, Reyes-Montes MR. Fungal diversity and Aspergillus in hospital environments. Ann Agric Environ Med. 2016; 23(2): 264-269. doi: $10.5604 / 12321966.1203888$

\section{Abstract}

Introduction and objective. Nosocomial invasive fungal infections, particularly aspergillosis, are an increasing problem in immunocompromised patients. The presented study evaluates fungal diversity and the presence of Aspergillus in air samples from two hospitals.

Materials and methods. Over the course of one year (rainy and dry seasons), the air was sampled from three areas in two hospitals ( 1 and 2 ) using a single-stage Andersen viable particle sampler (Thermo Scientific, Waltham, MA, USA). The fungi were identified by macro- and micromorphology, and the number of colony forming units (CFU) $/ \mathrm{m}^{3}$ air and their richness, abundance, and diversity were determined. Isolates Aspergillus genus were characterized by their thermotolerance.

Results. The CFU/m $\mathrm{m}^{3}$ air was similar at both hospitals during the two seasons, but different between the sampled areas. Results showed 10 fungal genera for hospital 1, and 8 for hospital 2. The most abundant were Penicillium, Cladosporium and Aspergillus. The thermotolerance test confirmed the identification of $A$. fumigatus section Fumigati. The highest growth rate was found in Aspergillus section Nigri.

Conclusion. Determining the fungal diversity in the two hospitals was important because all the species have the potential to be pathogenic, especially the section Fumigati.

\section{Key words}

fungal diversity, Aspergillus spp., airborne, thermotolerance

\section{INTRODUCTION}

Exposure to bioaerosols is one of the greatest threats to public health because of the adverse effects on humans, animals, and plants $[1,2,3]$. Bioaerosols are aerial suspensions of particles from living organisms, microorganisms or other biological materials $[4,5]$, the bioaerosols can be dispersed over long distances by air currents and then inhaled, ingested, or otherwise contacted by humans [3]. Fungi are an important component of the bioaerosols of the air and are widely distributed in soil, water, and decaying vegetation [6], and fungi can change benign superficial infections into invasive mycoses [6-11]. Most of the fungi in the environment, both indoors and outdoors, belong to the divisions Ascomycota, Basidiomycota, and mitosporic fungi [12], with Penicillium, Aspergillus, Cladosporium, and Alternaria the most

Address for correspondence: María del Rocío Reyes-Montes, Departamento de Microbiología y Parasitología, Facultad de Medicina, Universidad Nacional Autónoma de México (UNAM), Ciudad Universitaria No. 3000, México Cd. Mx., 04510, México.

E-mail: remoa@unam.mx

Received: 08 September 2015; accepted: 11 December 2015 abundant genera [13]. In intramural environments such as those of hospitals, the diversity of fungi is similar, but the concentration and abundance of conidia is associated with their growth in building materials, food, pots, bedding, dust, paint, etc.; under suitable temperature and moisture conditions, conidia grow and sporulate on these substrates, thus constituting a significant source of conidia and hyphal fragments in the air. Numerous studies have been conducted on the adverse effects on human health caused by fungi in intramural and extramural environments [11]. In most of these studies, the single-stage Andersen viable particle sampler (Thermo Scientific; Waltham, MA, USA) is the most frequently used air sampler [14-17] in the detection of colony forming units (CFU) per cubic meter of air, after which identification of the fungi is performed by culture or by molecular techniques $[14,15,17,18]$. Studies have shown that the highest percentage of nosocomial infections is caused by fungi such as Candida albicans and the previously mentioned filamentous fungi [19-22]. A genus that has emerged most often as an important cause of morbidity and high mortality in immunocompromised patients is Aspergillus [23,24]. Invasive aspergillosis (IA) and other infections caused by filamentous 
fungi occur in different groups of immunocompromised patients, including patients with haematologic malignancies [25] who have undergone transplantation [26], patients with congenital immunodeficiencies [27], and patients undergoing immunosuppressive drug therapy [28]. Therefore, the objective of this study was to assess fungal diversity and the presence of airborne fungi at two hospitals in Mexico City.

\section{MATERIALS AND METHOD}

Sampling area. Sampling was conducted from May - October 2012 (rainy season) and November 2012 - April 2013 (dry season) in two hospitals located in Mexico City: a specialty hospital, which houses nearly 1,400 patients per month, and the Institute of Ophthalmology, which can house 100 patients; the hospitals were designated 1 and 2, respectively. The areas sampled in hospital 1 were haematology, adult intensive care, and paediatric intensive care units, whereas the areas sampled in hospital 2 were the operating theatre, recovery room, and outpatient room. The sampling of air in different areas was always performed on the same day (Monday and Wednesday) and at the same time (10:00).

Air sampling procedure. Air samples were obtained with a single-stage Andersen viable particle sampler (Thermo Scientific; Waltham, MA, USA). This system impacts the microorganisms from the environment onto Sabouraud-agar medium (Bioxón, D.F., Mexico). The sampler was placed at a height of $1.5 \mathrm{~m}$ from the floor, in the center of each sampling area, and each sample was collected with a vacuum flow of 28.3 L/min for $15 \mathrm{~min}$. Three samples were collected from each sampling area [29].

Fungal examination of airborne samples. After three days of incubation at $28^{\circ} \mathrm{C}$, all the plates were examined and the colonies counted. For each sampled area, the average number of all the colonies grown on the three Sabouraudagar plates was calculated, and the number of $\mathrm{CFU} / \mathrm{m}^{3}$ air determined according to the manufacturer's protocol sampler. In addition, the $\mathrm{CFU} / \mathrm{m}^{3}$ air was calculated separately for each different colony observed on the plates. All the different colonies were identified by their macro and micromorphologies. The isolates grown on Sabouraudagar at $28^{\circ} \mathrm{C}$ for $4-7$ days were observed to identify the typical morphology of each fungus, including the colour and colonial texture. The micromorphological characteristics of all isolates were analyzed using the microculture method of Riddell [30]. The isolates with characteristics compatible with Aspergillus species were inoculated and incubated at $25^{\circ} \mathrm{C}$ in Czapek-Dox agar (Becton Dickinson, MD, USA) and potato dextrose agar (Bioxon) to identify the species using taxonomic keys [31]. Furthermore, the isolates identified in the different sections of Aspergillus were tested in assays of thermotolerance to corroborate those belonging to A. fumigatus section Fumigati. The assays were conducted as described by Frías-De-León et al. [32]. A suspension of $5 \times 10^{3}$ conidia/mL was prepared with PBST (phosphate buffered saline solution with tween 20) using a Neubauer chamber and inoculated in triplicate for each temperature (28 and $50^{\circ} \mathrm{C}$ ). Growth rate (GR) of all Aspergillus isolates studied was determined according to the model of Baranyi and Roberts [33].
Fungal diversity. The richness and abundance of organisms were determined in each area sampled at the two hospitals. The richness was obtained based on the number of species isolated in each sampling area; the abundance was determined by the number of occurrences of each microorganism in each area divided by the total CFU of each area and then multiplied by 100 . The fungal diversity was calculated for each hospital based on a matrix of the presence and abundance of the species using the Shannon-Wiener $(H)$ and Simpson indices and the software PAST version 1.89 (http://folk.uio. no/ohammer/past) [34].

Statistical analysis. Analysis of variance (ANOVA) was performed to determine if there were statistically significant differences in aero-conidial concentration $\left(\mathrm{CFU} / \mathrm{m}^{3}\right)$ between the dry and cold seasons of each sampling area, and between the hospitals. All tests were conducted at a significance level of 5\% using the software NCSS ver. 7.0 (www.ncss.com).

\section{RESULTS}

Quantification of CFU/ $\mathrm{m}^{3}$ in hospitals 1 and 2. A total of 432 air samples obtained in the two hospitals were studied. At both hospitals, the concentration of airborne fungi was similar, and no significant differences in the levels of fungi $\left(\mathrm{CFU} / \mathrm{m}^{3}\right)$ between the dry and rainy seasons $(\mathrm{p}>0.05)(\mathrm{Tab} .1)$ were observed.

Table 1. Colony forming units (CFU) in each area sampled in hospitals 1 and 2

\begin{tabular}{clcl}
\hline Hospital & Sampling area & $\begin{array}{l}\text { Rainy season } \\
\mathrm{CFU} / \mathrm{m}^{3} \pm \mathrm{SD}\end{array}$ & $\begin{array}{l}\text { Dry season } \\
\mathrm{CFU} / \mathrm{m}^{3} \pm \mathrm{SD}\end{array}$ \\
\hline 1 & Haematology & $85.98 \pm 13.87$ & $97.09 \pm 8.55$ \\
\hline 1 & Adult intensive care unit & $43.51 \pm 9.37$ & $40.22 \pm 10.03$ \\
\hline 1 & Paediatric intensive care unit & $41.24 \pm 8.09$ & $43.75 \pm 6.99$ \\
\hline 2 & Outpatient room & $56.30 \pm 14.77$ & $53.79 \pm 10.24$ \\
\hline 2 & Recovery room & $50.57 \pm 13.99$ & $53.59 \pm 6.66$ \\
\hline 2 & Operating theatre & $8.53 \pm 2.06$ & $8.95 \pm 2.69$ \\
\hline
\end{tabular}

$\mathrm{SD}=$ Standard Deviation

At hospital 1, the highest concentration of conidia in the air $\left(\mathrm{CFU} / \mathrm{m}^{3}\right)$ was recorded as follows (in descending order): haematology unit, adult intensive care ward, and paediatric intensive care ward. The differences in $\mathrm{CFU} / \mathrm{m}^{3}$ between the three areas sampled in hospital 1 were statistically significant $(\mathrm{p}<0.05)$. At hospital 2, the highest concentration of $\mathrm{CFU} / \mathrm{m}^{3}$ in the air was recorded as follows (in descending order): outpatient room, recovery room, and operating theatre. The differences in $\mathrm{CFU} / \mathrm{m}^{3}$ between the three areas sampled in hospital 2 were also statistically significant $(\mathrm{p}<0.05)$ (Tab. 1$)$.

Identification of fungi isolated in hospitals 1 and 2 by macromorphology and micromorphology. At hospital 1, the fungi detected were: Acremonium sp., Alternaria sp., Aspergillus sp., Aspergillus section Flavi, Aspergillus section Fumigati, Aspergillus section Nigri, Aspergillus section Terrei, Cladophialophora bantiana, Cladosporium sp., Fusarium proliferatum, Mucor sp., Paecilomyces sp., Penicillium sp., Rhizopus sp., R. stolonifer and Trichoderma sp. (Fig. 1). At hospital 2, the fungi detected were: Alternaria sp., Aspergillus 
sp., A. section Flavi, A. section Fumigati, A. section Nigri, A. section Terrei, Cladosporium sp., Mucor sp., Paecilomyces sp., Penicillium sp., P. griseofulvum, Trichoderma sp., Rhizopus sp., and R. stolonifer (Fig. 2).

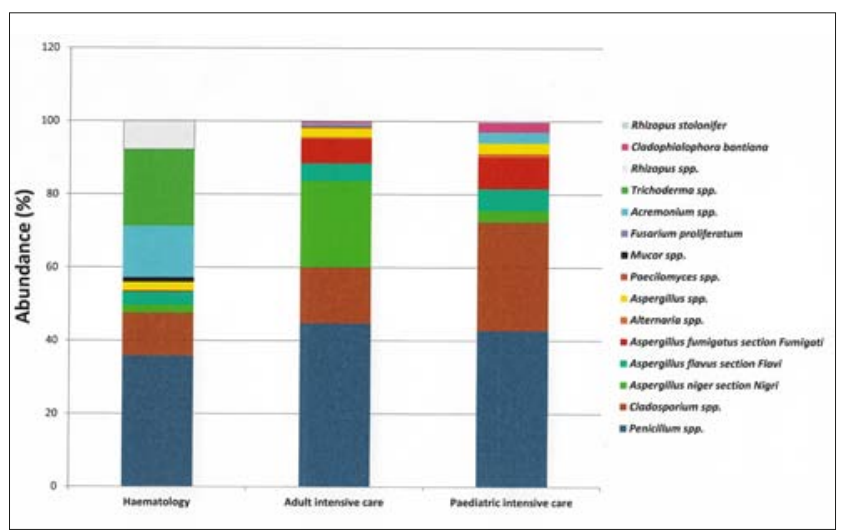

Figure 1. Richness and abundance of fungi in the sampled areas of hospital 1

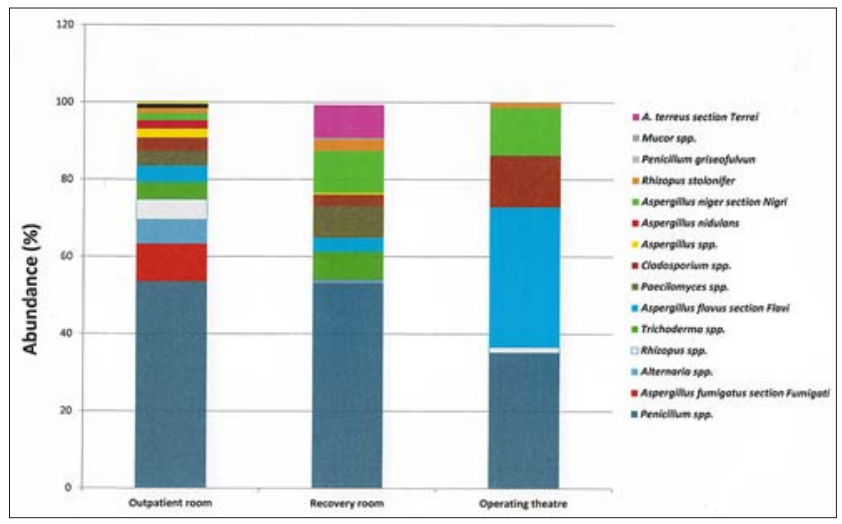

Figure 2. Richness and abundance of fungi in the sampled areas of hospital 2

Fungal diversity. The fungal diversity in hospital 1 showed a richness of fungi distributed as follows: 7 genera and 6 species were found in the adult intensive care unit, 6 genera and 5 species in the paediatric intensive care unit, and 7 genera and 5 species in the haematology unit. In hospital 2: 8 genera and 6 species in the outpatient consultation room, 8 genera and 5 species in the recovery room, and 4 genera and 3 species in the operating theatre (Figs. 1 and 2).

The most abundant fungi sampled in each area of hospital 1 were $A$. section Flavi, A. section Fumigati, A. section Nigri, Cladosporium sp., and Penicillium sp. in the pediatric intensive care unit; Acremonium sp., Cladosporium sp., Penicillium sp., Rhizopus sp. and Trichoderma sp. in haematology; A. section Flavi, A. section Fumigati, A. section Nigri, Cladosporium sp., and Penicillium sp. in adult intensive care (Fig. 1). The most abundant fungi sampled in each area of hospital 2 were: Alternaria spp., A. section Flavi, A. section Fumigati, Penicillium sp., Rhizopus sp., and Trichoderma sp. in outpatient consultation; A. section Nigri, A. section Terrei, Paecilomyces sp., Penicillium sp. and Trichoderma sp. in the recovery room; A. section Flavi, A. section Nigri, Cladosporium sp. and Penicillium sp. in the operating theatre (Fig. 2). The diversity values estimated by the ShannonWiener and Simpson indices revealed a slightly higher diversity in hospital 1 (Tab. 2).
Table 2. Fungal diversity in the different sampled areas in hospitals 1 and 2

\begin{tabular}{cccccc}
\hline & Hospital 1 & & \multicolumn{3}{c}{ Hospital 2 } \\
\hline $\begin{array}{c}\text { Sampled } \\
\text { area }\end{array}$ & $\begin{array}{c}\text { Simpson } \\
\text { Index }\end{array}$ & $\begin{array}{c}\text { Shannon } \\
\text { Index }\end{array}$ & $\begin{array}{c}\text { Sampled } \\
\text { area }\end{array}$ & $\begin{array}{c}\text { Simpson } \\
\text { Index }\end{array}$ & $\begin{array}{c}\text { Shannon } \\
\text { Index }\end{array}$ \\
\hline AICU & 0.7784 & 1.822 & OPR & 0.6593 & 1.668 \\
\hline HAEM & 0.7822 & 1.942 & RR & 0.6494 & 1.677 \\
\hline PICU & 0.7915 & 1.879 & OT & 0.6172 & 1.204 \\
\hline
\end{tabular}

AICU = Adult intensive care unit; HAEM = Haematology; PICU = Paediatric intensive care unit; $\mathrm{OPR}=$ Outpatient room; RR = Recovery room; $\mathrm{OT}=$ Operating theatre.

All the isolates of the genus Aspergillus from hospital 1 grew at $28^{\circ} \mathrm{C}$ (Tab. 3). The GR for the A. section Fumigati isolates was in the range of $13.90-19 \mathrm{~mm} /$ day and for $A$. section Nigri was in the range of $18.13-25.44 \mathrm{~mm} /$ day. The GR for A. section Flavi was in the range of $15.96-19.08 \mathrm{~mm} /$ day and for $A$. section Terrei was in the range of $8.17-8.87 \mathrm{~mm} /$ day. All the Aspergillus isolates from hospital 2 grew at $28^{\circ} \mathrm{C}$. The GR for A. section Fumigati isolates was in the range of 14.79$22.39 \mathrm{~mm} /$ day and for $A$. section Nigri was in the range of 20.49-25.69 mm/day. The GR for A. section Flavi was in the range of $14.88-22.52 \mathrm{~mm} /$ day and for $A$. section Terrei was in the range of $9.20-9.57 \mathrm{~mm} /$ day.

Only the isolates from hospitals 1 and 2 identified as A. section Fumigati grew at $50^{\circ} \mathrm{C}$ (Tab. 3). Isolates from hospital 1 presented a GR of $0.88-21.93 \mathrm{~mm} /$ day, whereas isolates from hospital 2 presented a range of $2.61-29.21 \mathrm{~mm} /$ day (Tab. 3), showing statistically significant differences $(\mathrm{p}<0.05)$ among their GR, both among and between isolates of hospital 1 and hospital 2.

Table 3. Growth rate of Aspergillus spp. isolates

\begin{tabular}{cccc}
\hline \multirow{2}{*}{ Hospital } & \multirow{2}{*}{ Section } & \multicolumn{2}{c}{ Growth rate $(\mathrm{mm} /$ day) \pm SD } \\
\cline { 3 - 4 } & & $28^{\circ} \mathrm{C}$ & $50^{\circ} \mathrm{C}$ \\
\hline 1 & Fumigati & $16.95 \pm 1.63$ & $6.53 \pm 5.13$ \\
\hline 1 & Nigri & $22.95 \pm 1.92$ & $\mathrm{NA}$ \\
\hline 1 & Flavi & $17.07 \pm 1.19$ & $\mathrm{NA}$ \\
\hline 1 & Terrei & $8.54 \pm 0.35$ & $\mathrm{NA}$ \\
\hline 2 & Fumigati & $17.94 \pm 2.16$ & $12.61 \pm 7.13$ \\
\hline 2 & Nigri & $23.04 \pm 1.39$ & $\mathrm{NA}$ \\
\hline 2 & Flavi & $18.34 \pm 2.72$ & $\mathrm{NA}$ \\
\hline 2 & Terrei & $9.38 \pm 0.26$ & $\mathrm{NA}$ \\
\hline
\end{tabular}

$\mathrm{SD}=$ Standard deviation; $\mathrm{NA}=$ Not applicable

\section{DISCUSSION}

In recent decades, there has been a global increase in nosocomial fungal infections because of advances in increasingly effective, but also more aggressive, medical and surgical therapies [35]. Invasive fungal diseases caused by filamentous fungi are associated with high morbidity and mortality, which is partially because of the difficulty in making an early diagnosis, thus resulting in a delay in starting appropriate treatment. Although fungi have several routes of entry into the host, the most common is through inhalation of propagules; thus, maintaining good air quality in critical areas of hospitals is required to reduce the incidence of invasive fungal infections. Therefore, the presented study is aimed at detecting airborne fungi in the environment of 
different areas of two hospitals (1 and 2) to illustrate the occurrence of fungal species. The results obtained are in accordance with the results of other aeromycology studies from Mexico and Brazil [36-38].

During the sampling period, the concentration of fungi in the air $\left(\mathrm{CFU} / \mathrm{m}^{3}\right)$ at both hospitals was similar for both the dry and rainy seasons, regardless of the conditions or structure of each sampling area. The $\mathrm{CFU} / \mathrm{m}^{3}$ in the sampled areas of the two hospitals showed averages above $40.22 \mathrm{CFU} / \mathrm{m}^{3}$, with the exception of the operating theatre in hospital 2, which produced values of 8.53 and 8.95 for the rainy and dry seasons, respectively. The fungal burden found in the sampled areas of the two hospitals is inconsistent with that reported in other countries $[28,29]$; however, the $\mathrm{CFU} / \mathrm{m}^{3}$ in the operating theatre is consistent with such reports $\left(5-10 \mathrm{CFU} / \mathrm{m}^{3}\right)$, which can be explained by the stringent hygienic measures in operating theatres. Similarly, there are no established criteria at the institutional level in Mexico regarding the ranges of $\mathrm{CFU} / \mathrm{m}^{3}$ that are considered acceptable, since only one study of this type has been reported [38]. The homogeneity in the number of $\mathrm{CFU} / \mathrm{m}^{3}$ found during the two seasons (rainy and dry) can be explained by the similarity between these season in Mexico City, compared with countries of North America and Europe, where seasons are marked by abrupt changes in ambient temperature and a true separation occurs between intramural and extramural environments, which does not happen in Mexico.

In both hospitals, the fungal diversity was similar, with Penicillium spp., Cladosporium spp, A. section Nigri, $A$. section Flavi, and A. section Fumigati, which are all medically relevant, and the most abundant in both hospitals. These results are consistent with those reported by Hao et al. [39], who examined the environmental fungal load of two hospitals in China and demonstrated that Penicillium spp., Aspergillus spp., Cladosporium spp., Alternaria spp., and Fusarium spp. were present in the air, on surfaces, and in the tap water. They also reported that the fungal load fluctuated during the year of air sampling, and the highest densities of these microorganisms were observed during the summer and spring. Azimi et al. [40] also found that Penicillium spp., Aspergillus spp., and Cladosporium were the most common genera in different hospitals areas. The diversity of fungi found in this work can be explained because fungi suspended in the atmosphere can be transported quickly as bioaerosols over great distances with the movement of air, which represents the optimal mechanism of dispersion [41]. Certain fungi have developed specialized adaptations that favour their survival and dispersal in the atmosphere, with their transport performed on dust particles, fragments of leaves, skin, clothing fibers, or in drops of water [42]. The physicochemical conditions of the atmosphere do not favour the growth or survival of microorganisms; thus, the majority can only survive in the atmosphere for a short period of time. However, fungal conidia are life forms with longer survival rates and have several properties that contribute to their ability to survive in the atmosphere, such as thick walls, which protect them from desiccation, and pigment (melanin), which aids protects gainst ultraviolet radiation [43]. Additionally, conidia possess other adaptations, such as thermotolerance and nutritional versatility, which allows them to utilize a wide range of carbon and nitrogen sources, as in the case of the genus Aspergillus [43]. Also, their hydrophobin-rich conidial external layer allows them to remain suspended in the air without settling, because this cysteine-rich proteins are related to the high surfactant activity of fungi; hydrophobins selfassemble at the hydrophilic-hydrophobic interface to form an amphipathic monolayer $[44,45]$. These molecules reduce the surface tension of the medium or substrate on which the fungus grows, allowing it to break the air-water interface and prevent hydrosaturation to maintain gas permeability. The degree of hydrophobicity among fungi ranges from mild to highly hydrophobic, which affects the efficiency of the spore dispersion capacity; for example, conidia from A. fumigatus are significantly more hydrophobic than other species in this genus, allowing them to remain in the air $[44,45]$.

Undoubtedly, the presence of these microorganisms in hospital environments is a warning for more stringent control measures because among these fungi are species of the genus Aspergillus, which is considered the main cause of invasive fungal diseases by filamentous fungi in immunocompromised patients, resulting in high mortality rates of $40-90 \%$ [46]. Moreover, invasive fungal diseases caused by filamentous fungi other than Aspergillus spp. have also increased in frequency and mortality in recent years, especially in immunocompromised patients. The following fungi must be controlled for depending on the susceptibility factors of different hosts: Mucorales, such as Mucor, Rhizopus, and Lichtheimia, Fusarium, Scedosporium, Acremonium, Penicillium, Paecilomyces, Trichoderma, and dematiaceous fungi, such as Bipolaris, Exophiala, Alternaria, and Cladosporium [35]. Invasive fungal diseases caused by these fungi are less common than those caused by the genus Aspergillus; however, Penicillium spp. can cause certain types of asthma [47], and Cladosporium spp. may be associated with changes in lung function in children [48]. In addition, these fungi are usually more virulent and difficult to treat because of their resistance to most of the available drugs and type of affected patient, with those receiving haematologic treatment or solid organ transplants generally more affected [35].

Thermotolerance was conducted at $28^{\circ} \mathrm{C}$ and $50^{\circ} \mathrm{C}$ to confirm the identification of the A. fumigatus section Fumigati, because thermotolerance can be used to distinguish A. fumigatus from other species of clinical significance belonging to other sections. The Fumigati section [49] can be distinguished because of its ability to grow at temperatures of $55^{\circ} \mathrm{C}$ and survive at $75^{\circ} \mathrm{C}$, allowing the organism to grow in decaying organic matter and infect mammalian hosts $[50,51]$. The results of the presented study revealed that the isolates identified as A. section Fumigati grew at 28 and $50^{\circ} \mathrm{C}$. However, the fungi identified as $A$. section Flavi, $A$. section Nigri, and $A$. section Terrei only grew at $28^{\circ} \mathrm{C}$. Thus, this phenotypic characteristic is important for confirmation of identification of A. fumigatus section Fumigati [51].

The GR assays of all the isolates of the genus Aspergillus were performed to identify differences which were observed between the GRs of the isolates of $A$. section Fumigati at $50^{\circ} \mathrm{C}$. The ability of these fungi to resist high temperatures may play a crucial role in the selection and promotion of pathogenic species, such as $A$. section Fumigati, which is a species that adapts to extreme changes in environmental conditions, thus allowing it to develop invasive infections because the microenvironment provided by the human body appears to supply excellent conditions for its growth and invasion. The isolates of $A$. flavus and $A$. niger cannot adapt to similar conditions because they cannot withstand high temperatures [52]. The faster GRs at $28^{\circ} \mathrm{C}$ corresponded 
to isolates of $A$. section Nigri, followed by A. section Flavi, $A$. section Fumigati, and $A$. section Terrei from both hospitals. This result was consistent with that of Marin et al. [53], who observed that the growth of conidia occurs more rapidly in A. section Nigri at temperatures between $28-30^{\circ} \mathrm{C}$. However, despite the abundance and high GR of $A$. section Nigri, it is less thermotolerant than $A$. section Fumigati because its optimal growth temperature is $30^{\circ} \mathrm{C}$. Thus, it is difficult for $A$. section Nigri to germinate at $37^{\circ} \mathrm{C}$, which is the temperature of the human body. Perhaps this is a determining factor for why the nosocomial cases of aspergillosis are primarily caused by $A$. fumigatus and not $A$. niger.

The isolation of $A$. section Terrei reinforces the findings of Rüping et al. [54] who reported its presence in hospital environments, suggesting that its incidence has increased in cases of IA.

\section{CONCLUSIONS}

The airborne fungi in both hospitals was similar, highlighting Aspergillus section Fumigati, the filamentous fungus responsible for invasive aspergillosis worldwide. The current study presents one of the first to be performed in Mexico for evidence of airborne fungi in nosocomial environments. Furthermore, the isolation, identification and characterization of airborne fungi in hospital environments is a key task, because most of these fungi have the potential to be pathogenic, particularly for patients in intensive care and haematology units. Additionally, the presence of the genus Aspergillus within hospital environments should be monitored in areas that house immunosuppressed patients susceptible to exposure to this pathogen. These findings support the necessity to develop stricter safety protocols that would substantially reduce morbidity and mortality in patients and high hospital costs.

\section{Acknowledgements}

The study was supported by PAPIIT-DGAPA (IN219212), UNAM, as a part of the PhD thesis of Erick Obed MartínezHerrera, a student of the Doctorado en Ciencias Biológicas y de la Salud at the Universidad Autónoma Metropolitana and the scholarship of the Consejo Nacional de Ciencia y Tecnología-Mexico (CONACyT-Mexico, Reference Number-554689). The authors thank César Guerrero Guerra for their technical advice.

\section{Author's Contributions}

Erick Obed Martínez-Herrera, María Guadalupe FríasDe-León and Esperanza Duarte-Escalante conducted all the experiments. María del Carmen Calderón-Ezquerro, María del Carmen Jiménez-Martínez and Gustavo AcostaAltamirano, conducted the sampling procedures in the two hospitals. Erick Obed Martínez-Herrera, Facundo RiveraBecerriland Conchita Toriello conducted statistical analysis, and Facundo Rivera-Becerriland Conchita Toriello provided a critical review of the manuscript. María del Rocío ReyesMontes was involved in the study design, analysis and interpretation of results and drafted the manuscript. María Guadalupe Frías-De-León and Esperanza Duarte-Escalante contributed to data interpretation and improvement of the manuscript. All of the authors read and approved the final version of the manuscript.

\section{REFERENCES}

1. Fernstrom A, Goldblatt M. Aerobiology and its role in the transmission of infectious diseases. J Pathol. 2013; 2013: 1-C13.

2. Durugbo EU, Kajero AO, Omoregie EI, Oyejide NE. A survey of outdoor and indoor airborne fungal spora in the Redemption City, Ogun State, south-western Nigeria. Aerobiologia. 2013; 29(2): 201-216.

3. Menezes EA, Trindade ECP, Costa MM, Freire CCF, Cavalcante MS, Cunha F. Airborne fungi isolated from Fortaleza City, State of Ceara, Brazil. Rev Inst Med Trop Sao Paulo. 2004; 46(3): 133-137.

4. Kasprzyk I. Aeromycology - main research fields of interest during the last 25 years. Ann Agric Environ Med. 2008; 15(1): 1-7.

5. Srikanth P, Sudharsanam S, Steinberg R. Bio-aerosols in indoor environment: Composition, health effects and analysis. Indian J Med Microbiol. 2008; 26(4): 302-312.

6. Sen B, Asan A. Fungal flora in indoor and outdoor air of different residential houses in Tekirdag City (Turkey): seasonal distribution and relationship with climatic factors. Environ Monit Assess. 2009; 151(1-4): 209-219.

7. Simon-Nobbe B, Denk U, Pöll V, Rid R, Breitenbach M. The spectrum of fungal allergy. Int Arch Allergy Immunol. 2008; 145(1): 58-86.

8. Hedayati MT, Mayahi S, Aghili R, Goharimoghadam K. Airborne fungi in indoor and outdoor of asthmatic patients' home, living in the city of Sari. Iran J Allergy Asthma Immunol. 2005; 4(4): 189-191.

9. Lentino JR, Rosenkranz MA, Michaels JA, Kurup VP, Rose HD, Rytel MW. Nosocomial aspergillosis: a retrospective review of airborne disease secondary to road construction and contaminated air conditioners. Am J Epidemiol. 1982; 116(3): 430-437.

10. Vonberg RP, Gastmeier P. Nosocomial aspergillosis in outbreak settings. J Hosp Infect. 2006; 63(3): 246-254.

11. Sepahvand A, Shams-Ghahfarokhi M, Allameh A, Razzaghi-Abyaneh M. Diversity and distribution patterns of airborne microfungi in indoor and outdoor hospital environments in Khorramabad, Southwest Iran. Jundishapur J Microbiol. 2013; 6(2): 86-192.

12. Guarro J. Taxonomía y biología de los hongos causantes de infección en humanos. Enferm Infecc Microbiol Clin. 2012; 30(1): 33-39.

13. de Ana SG, Torres-Rodríguez JM, Ramírez EA, García SM, BelmonteSoler J. Seasonal distribution of Alternaria, Aspergillus, Cladosporium and Penicillium species isolated in homes of fungal allergic patients. J Investig Allergol Clin Immunol. 2006; 16(6): 357-363.

14. Mobin M, do Amparo Salmito M. Fungus microbiota in air conditioners in intensive care units in Teresina, Piauí. Rev Soc Bras Med Trop. 2006; 39(6): 556-559.

15. Cárdenas MX, Cortes JA, Parra CM. Aspergillus spp. in risk areas of transplant patients in a university hospital. Rev Iberoam Micol. 2008; 25(4): 232-236.

16. Eames I, Tang JW, Li Y, Wilson P. Airborne transmission of disease in hospitals. J R Soc Interface. 2009; 6(Suppl 6): S697-S702.

17. Kim KY, Kim YS, Kim D. Distribution characteristics of airborne bacteria and fungi in the general hospitals of Korea. Ind Health. 2010; 48(2): 236-243.

18. Augustowska M, Dutkiewicz J. Variability of airborne microflora in a hospital ward within a period of one year. Ann Agric Environ Med. 2006; 13(1): 99-106.

19. Perdelli F, Cristina ML, Spagnolo AM, Dallera M, Ottria G, Lombardi R, Grimaldi M, Orlando P. Fungal contamination in hospital environments. Infect Control Hosp Epidemiol. 2006; 27(1): 44-47.

20. Faure O, Fricker-Hidalgo H, Lebeau B, Mallaret MR, AmbroiseThomas P, Grillot R. Eight-year surveillance of environmental fungal contamination in hospital operating rooms and haematological units. J Hosp Infect. 2002; 50(2): 155-160.

21. Fox BC, Chamberlin L, Kulich P, Rae EJ, Webster LR. Heavy contamination of operating room air by Penicillium species: Identification of the source and attempts at decontamination. Am J Infect Control. 1990; 18(5): 300-306.

22. Panagopoulou P, Filioti J, Farmaki E, Maloukou A, Roilides E. Filamentous fungi in a tertiary care hospital: environmental surveillance and susceptibility to antifungal drugs. Infect Control Hosp Epidemiol. 2007; 28(1): 60-67.

23. Clark TA, Hajjeh RA. Recent trends in the epidemiology of invasive mycoses. Curr Opin Infect Dis. 2002; 15(6): 569-574.

24. Denning DW. Invasive aspergillosis. Clin Infect Dis. 1998;26(4):781-803.

25. Martino R, Subira M. Invasive fungal infections in hematology: new trends. Ann Hematol. 2002; 81(5): 233-243.

26. Marr KA, Carter RA, Crippa F, Wald A, Corey L. Epidemiology and outcome of mould infections in hematopoietic stem cell transplant recipients. Clin Infect Dis. 2002; 34(1): 909-917. 
27. Winkelstein JA, Marino MC, Johnston RB, Boyle J, Curnutte J, Gallin JI, Malech HL, Holland SM, Ochs H, Quie P, Buckley RH, Foster CB Chanock SJ, Dickler H. Chronic granulomatous disease: report on a national registry of 368 patients. Medicine. 2000; 79(3): 155-169.

28. De Rosa FG, Shaz D, Campagna AC, Dellaripa PE, Khettry U, Craven DE. Invasive pulmonary aspergillosis soon after therapy with infliximab, a tumor necrosis factor-alpha-neutralizing antibody: a possible healthcare-associated case? Infect Control Hosp Epidemiol. 2003; 24(7): 477-482.

29. Andersen Viable Particle Sampler, Thermo Electron Corporation. Environmental Instruments. Series 10-800. Single Stage Viable Sampler. Instruction manual P/N 100074-00. Massachusetts, USA: Thermo Electron Corporation, 2003.p. 13.

30. Ridell R. Permanent stained micological preparations obtained by slide culture. Mycology. 1950; 42(2): 265-270.

31. Raper KB, Fennel DI. The genus Aspergillus. Williams and Wilkins (Baltimore, MD, USA) Publisher, 1965.

32. Frías De León MG, Zavala-Ramírez M, Córdoba S, Zúñiga G, DuarteEscalante E, Pérez-Torres A, Zepeda-Rodríguez A, López-Martínez I, Buitrago MJ, Reyes-Montes MR. Phenotypic characteristics of isolates of A. fumigatus from different geographic origins and their relationships with genotypic characteristic. BMC Infect Dis. 2011; 11: 116.

33. Baranyi J, Roberts TA. A dynamic approach to predicting bacterial growth in food. Int J Food Microbiol. 1994; 23(3-4): 277-294.

34. Hammer O, Harper DAT, Ryan PD. PAST, Paleontological statistics software package for education and data analysis. Palaeontol Electronica. 2001; 4(1):1-9.

35. Pemán J, Salavert M. Epidemiology and prevention of nosocomial invasive infections by filamentous fungi and yeasts. Enferm Infec Microbiol Clin. 2013; 31(5): 328-341.

36. Martins-Diniz JN, da Silva RA, Miranda ET, Mendes-Giannini MJ. Monitoring of airborne fungus and yeast species in a hospital unit. Rev Saude Publica. 2005; 39(3): 398-405.

37. Cordeiro RA, Brilhante RS, Pantoja LD, Moreira Filho RE, Vieira PR, Rocha MF, Monteiro AJ, Sidrim JJ. Isolation of pathogenic yeasts in the air from hospital environments in the city of Fortaleza, northeast Brazil. Braz J Infect Dis. 2010; 14(1): 30-34.

38. Ríos-Yuil JM, Arenas R, Fernández R, Calderón-Ezquerro M, Rodriguez-Badillo R. Aeromycological study at the intensive care unit of the "Dr. Manuel Gea Gonzalez" General Hospital. Braz J Infect Dis. 2012; 16(5): 432-435.

39. Hao ZF, Ao JH, Hao F, Yang Rong-ya RY, Zhu H, Zhang J. Environment surveillance of filamentous fungi in two tertiary care hospitals in China. Chin Med J (Engl). 2011; 124(13): 1970-1975.
40. Azimi F, Naddafi K, Nabizadeh R, Hassanvand MS, Alimohammadi M, Afhami S, Musavi SN. Fungal air quality in hospital rooms: a case study in Tehran, Iran. J Environ Health Sci Eng. 2013; 11(1): 30.

41. Warris A, Voss A, Verweij PE. Hospital sources of Aspergillus: New routes of transmission? Rev Iberoam Micol. 2001; 18(4): 156-162.

42. Hoseinzadeh E, Reza Samarghandie M, Ghiasian SA, Alikhani MY, Roshanaie G. Evaluation of bioaerosols in five educational hospitals wards air in Hamedan, during 2011-2012. Jundishapur J Microbiol. 2013; 6(6): e10704.

43. Abad A, Fernández-Molina JV, Bikandi J, Ramírez A, Margareto J, Sendino J, Hernando FL, Pontón J, Garaizar J, Rementeria A. What makes Aspergillus fumigatus a successful pathogen? Genes and molecules involved in invasive aspergillosis. Rev Iberoam Micol. 2010; 27(4):155-182.

44. Bayry J, Aimanianda V, Guijarro JI, Sunde M, Latgé JP. Hydrophobinsunique fungal proteins. PLoS Pathog. 2012; 8(5): 1-4.

45. Kwon-Chung KJ, Sugui JA. Aspergillus fumigatus-What makes the species a ubiquitous human fungal pathogen? PLoS Pathog. 2013; 9(12): 1-4.

46. Alangaden GJ. Nosocomial fungal infections: epidemiology, infection control, and prevention. Infect Dis Clin North Am. 2011; 25(1): 201-225.

47. Licorish K, Novey HS, Kozak P, Fairshter RD, Wilson AF. Role of Alternaria and Penicillium spores in the pathogenesis of asthma. J Allergy Clin Immunol. 1985; 76(6): 819-825.

48. Chen BY, Chao HJ, Wu CF, Kim H, Honda Y, Guo YL. High ambient Cladosporium spores were associated with reduced lung function in schoolchildren in a longitudinal study. Sci Total Environ. 2014; 481: 370-376.

49. Balajee SA, Houbraken J, Verweij PE, Hong S-B, Yaghuchi T, Varga J, Samson RA. Aspergillus species identification in the clinical setting. Stud Mycol. 2007; 59: 39-46.

50. Ryckeboer J, Mergaert J, Coosemans J, Deprins K, Swings J. Microbiological aspects of biowaste during composting in a monitored compost bin. J Appl Microbiol. 2003; 94(1): 127-137.

51. Maheshwari R, Bharadwaj G, Bhat MK. Thermophilic fungi: their physiology and enzymes. Microbiol Mol Biol Rev. 2000; 64(3): 461-488.

52. Araujo R, Gonçalves-Rodrigues A. Variability of germinative potential among pathogenic species of Aspergillus. J Clin Microbiol. 2004; 42(9): 4335-4337.

53. Marín S, Sanchis V, Sáenz R, Ramos AJ, Vinas I, Magan N. Ecological determinants for germination and growth of some Aspergillus and Penicillium spp. from maize grain. J Appl Microbiol. 1998; 84(1): 25-36.

54. Rüping MJGT, Gerlach S, Fischer G, Lass-Flörl C, Hellmich M, Vehreschild JJ, Cornely OA. Environmental and clinical epidemiology of Aspergillus terreus: data from a prospective surveillance study. J Hosp Infect. 2011; 78(3): 226-230. 